\title{
Reflexiones metacientíficas acerca de la enseñanza de la ciencia. Posibles aportes desde la perspectiva comunicativa de Jürgen Habermas
}

\section{"Metascientific Reflections on the Teaching of Science. Possible Contributions from the Communicative Perspective of Jürgen Habermas"}

\author{
Juan Alberto Fraiman"
}

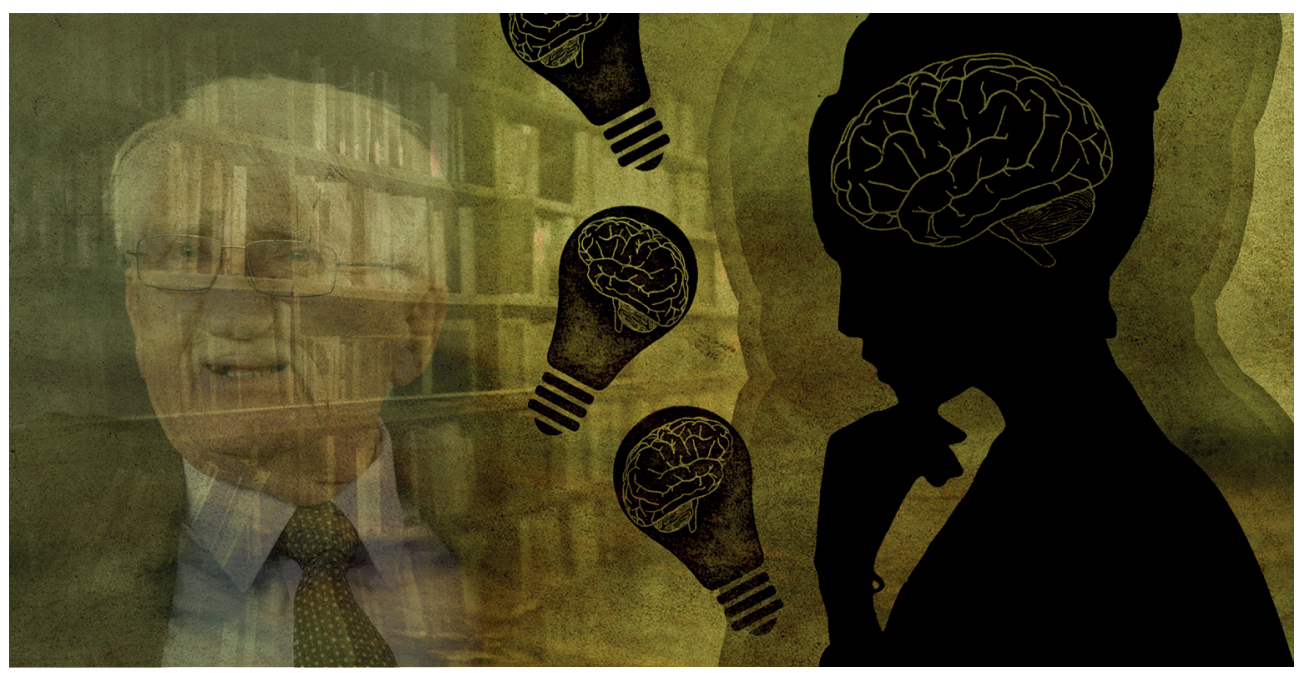

\section{Resumen}

En el presente artículo abordaremos, en primer lugar, la relevancia de la enseñanza de la ciencia, en sus distintos niveles, desde el punto de vista metacientífico. Luego, desarrollaremos la concepción de racionalidad comunicativa, en sus distintos aspectos, del pensador alemán contemporáneo Jürgen Habermas. Ello nos permitirá pensar la enseñanza de la ciencia como un ámbito fundamental para promocionar el pensamiento crítico.

Palabras clave: enseñanza de la ciencia, racionalidad comunicativa, crítica

Citar este artículo como: Fraiman, J.A. (2020). Reflexiones metacientíficas acerca de la enseñanza de la ciencia. Posibles aportes desde la perspectiva comunicativa de Jürgen Habermas. Revista Papeles, 12(24), 27-45.

Fecha de entrega: noviembre 10 de 2020. Fecha de aceptado: enero 27 de 2021.

* Doctor en ciencias sociales (Universidad Nacional de Entre Ríos, Argentina). Profesor adjunto ordinario de Epistemología en la Universidad Nacional de Entre Ríos (UNER) y en la Universidad Autónoma de Entre Ríos (UADER). Correo electrónico: juanfraiman@hotmail.com 


\begin{abstract}
In this article we will deal firstly with the relevance of the Science Teaching, at its different levels, from a metascientific point of view. Then, we will develop the conception of communicative rationality, in its various aspects, of the contemporary German thinker Jürgen Habermas. This will allow us to think of the Teaching of Science as a fundamental area for promoting critical thinking.
\end{abstract}

Keywords: science teaching, communicative rationality, criticism.

\title{
1. Presentación
}

En el presente artículo se llevará a cabo un abordaje metacientífico de la enseñanza de la ciencia (en adelante, EC), tomando en consideración la concepción comunicativa de la racionalidad en Jürgen Habermas.

Por una parte, se ha pensado ya de manera extensa en las contribuciones de una epistemología o filosofía de la ciencia a las didácticas de las distintas disciplinas científicas. Se ha mostrado el papel de la reflexión metacientífica en el método para mejorar la comprensión acerca de la ciencia; el abordaje filosófico proporciona también recursos para potenciar las habilidades cognitivas de aprendizaje e incrementar el rigor lógico en el pensamiento; proporciona también buenos argumentos y fundamentos en un diseño curricular y en una organización de la enseñanza, además de contribuir a la formación integral de los ciudadanos en torno al conocimiento y desarrollo científico (Adúriz-Bravo, 2005, 11-12).

Sin embargo, es menos frecuente tal relación en un sentido inverso; es decir, la enseñanza de la ciencia desde un interés metacientífico. Esto significaría, por caso, interrogarse acerca de la relevancia o el lugar de la enseñanza en la comprensión general de la ciencia y en la promoción de un pensamiento crítico.

Normalmente, cuando se interroga acerca de los procesos de configuración de las imágenes de la ciencia, aparece destacado el problema de la divulgación o comunicación pública, la concepción de la ciencia que poseen los propios científicos y cómo la filosofía de la ciencia puede contribuir o ingresar en un diálogo con ambos actores sociales. En la búsqueda de un entendimiento adecuado de la ciencia, se debe indagar especialmente en la interacción entre ellos (Olivé, 2000, 42-43).

En ese marco, es preciso analizar cómo la EC se articula con las representaciones de la ciencia que emergen no solo en la vida pública sino también en el ámbito propiamente científico. E interrogar hasta qué punto la EC, en los distintos niveles educativos, es también relevante para conformar determinada imagen de la ciencia.

De modo que si la Epistemología, junto con otras disciplinas metacientíficas como la historia y la sociología de la ciencia, se ocupan de problematizar imágenes inadecuadas de la ciencia (Adúriz Bravo, 2011), por así decirlo, debe también prestar atención a la EC, pensar sus mecanismos y su conexión con otras esferas sociales relevantes.

¿Pero cómo entender a la EC?, ¿cuáles serían sus principales características y finalidades? Las respuestas a esas preguntas estarán supeditadas a la postura metateórica adoptada. Por ejemplo, una mirada estandarizada o convencional sobre la ciencia, supondría que la EC consistiría fundamentalmente en los intentos de traducir o transmitir, de la manera más asequible posible, el conocimiento científico a un público todavía no iniciado, diseñando, para ese propósito, distintos recursos y 
estratégicas didácticas. En consecuencia, la EC conformaría una instancia posterior y más bien subordinada a la producción efectiva del conocimiento científico.

Frente a ello, se podría oponer la idea de que la EC conforma un tipo de discurso específico sobre la ciencia (Palma, 2008: 69); no se confunde ni constituye un mero apéndice de la producción científica y posee además una relevancia central en la percepción de la ciencia no solo para el público no experto sino también para aquellos que llevan adelante la práctica científica, o sea, los mismos científicos.

En ese sentido, proponemos la consideración de la EC como punto de convergencia y correa de transmisión de sentido en la percepción global de la ciencia. Tal afirmación supone, al mismo tiempo, una discusión con una concepción metateórica estandarizada de la ciencia que subyacería en una formulación de la EC más convencional.

Bajo ese enfoque, creemos que se pueden abordar mejor algunas cuestiones fundamentales de la EC, tales como: ¿cuáles serían los objetivos primordiales y legítimos de una EC? Y ¿cómo debería ser una EC de calidad o excelencia?

Sin dudas, las respuestas pueden diferir según el nivel de enseñanza aludido; no es idéntico en la educación básica comparada con el grado superior, mayormente destinado a formar futuros científicos. No obstante, al menos dos aspectos podrían estar atravesando los distintos espacios en donde se enseña ciencia: el hecho de que allí se instaura sentido acerca de lo que es la ciencia y, en segundo lugar, la convicción de que enseñando ciencia se promueve, de alguna manera, el pensamiento crítico.

En efecto, suele afirmarse también que la EC es fundamental para la promoción de la reflexión crítica. Aunque también se ha señalado que una EC convencional, en el marco de una epistemología estandarizada, puede fácilmente conducir a la dirección contraria, a la reafirmación de posturas dogmáticas de cuño cientificista, desvirtuando completamente uno de sus fines esenciales.

Por esa razón, consideramos necesario incorporar la perspectiva comunicativa del pensador contemporáneo alemán Jürgen Habermas, en lo que hace a su noción de racionalidad. De esa manera, planteamos pensar a la ciencia y a la EC en relación a las potencialidades del lenguaje para la crítica, el diálogo y la reflexión.

En suma, nuestro artículo presentará un abordaje del problema de la EC desde una perspectiva metacientífica, destacando su importancia como discurso específico en la configuración de la percepción o imagen general de la ciencia, que puede además pensarse como una instancia fundamental para desarrollar o promover el pensamiento crítico; en particular, si lo interpretamos, desde una concepción teórica habermasiana. En ese sentido, sostendremos que la noción de racionalidad desarrollada por Jürgen Habermas resultará muy fructífera para resaltar la importancia de la EC en la formación de un pensamiento dinámico, crítico y abierto.

Cuando se interroga acerca de los procesos de configuración de las imágenes de la ciencia, aparece destacado el problema de la divulgación o comunicación pública, la concepción de la ciencia que poseen los propios científicos y cómo la filosofía de la ciencia puede contribuir o ingresar en un diálogo con ambos actores sociales. 


\section{La Enseñanza de la ciencia}

En principio, al referirnos a la EC estamos aludiendo al acto de impartir conocimientos científicos a través del sistema formal de educación, en todos sus niveles: inicial, básico o elemental, medio, preuniversitario y universitario.

Por cierto, se trata de un vasto campo de desarrollo histórico que bien podría denominarse la educación científica, consustancial al propio despliegue de las instituciones educativas modernas. En particular, desde el siglo XVIII, floreció una tradición europea ilustrada que, prosiguiendo a la revolución científica del siglo anterior - con sus grandes nombres, Galileo, Newton, Kepler (Beltrán, 1995)—, se proponía una educación libre y laica; una escolaridad no controlada por la Iglesia, en manos de un Estado secular, ocupado fundamentalmente en divulgar los frutos del trabajo científico, en pos de los ideales de la Ilustración: emancipación política, progreso social, igualdad económica y libertad de expresión (Matthews, 2017, 60-63).

En aquella época, las dificultades en el acceso a los conocimientos científicos y el diseño de métodos de enseñanza no constituyeron inquietudes ajenas a los propios filósofos e impulsores de la Ilustración. Desde las principales figuras que instituyeron la enciclopedia francesa en el siglo XVIII, tal preocupación siguió presente al menos a inicios del siglo XX en importantes pensadores como Ernst Mach, precursor del Positivismo Lógico en Viena, o John Dewey, eminente representante de la filosofía pragmatista en los EE UU (Matthews, 2017, 67-87).

Pese a ello, la EC fue implementada inicialmente como el desarrollo de clases magistrales y demostraciones de laboratorios por parte de los propios científicos, en su rol como docentes, bajo un modelo de la enseñanza como transmisión/recepción lineal de conocimientos y prácticas. Al mismo tiempo, toda la formación de pregrado se subordina a las exigencias universitarias, o sea, a la preparación del futuro científico.

De la misma manera, tal concepción de la enseñanza se encuentra estrechamente comprometida con una concepción más bien espontánea y del sentido común de la ciencia como un conjunto de datos acumulados que deben transmitirse o, a lo sumo, traducirse según el requerimiento de nivel de educación (Acevedo Díaz, 2004).

A mediados del siglo XX el viejo modelo educativo se va resquebrajando. Una variedad de corrientes comienzan a proliferar y debatir en las recientes revistas especializadas, con preocupaciones más delimitadas en la enseñanza y el aprendizaje de las ciencias. Estimulado también por la crítica metateórica a las concepciones estandarizadas de la ciencia ${ }^{1}$, ganan terreno las visiones constructivistas de la enseñanza aplicada a la ciencia (Badillo, 2002).

Surgen así las llamadas didácticas de las ciencias que van indicando el carácter cada vez más autónomo de la EC como ámbito separado de la investigación científica. Las didácticas se preocupan por el problema de la adquisición de conocimientos y aptitudes en el contexto de una clase o de una situación de laboratorio, desarrollando recursos y estrategias de enseñanza, atendiendo a los procesos de aprendizajes y sus obstáculos en los alumnos. El reconocimiento de las dificultades y la complejidad en los mecanismos psíquicos, lingüísticos, sociales y culturales que intervienen en los procesos de EC, obligarán al diálogo con la Psicología Cognitiva, la

1 Impulsadas especialmente luego del enorme impacto que suscitó la publicación, en el año 1962, de La Estructura de las Revoluciones científicas de Thomas Kuhn (2004) al interior de la filosofía de la ciencia, pero también fuera de ella. 
Lingüística y la teoría del aprendizaje, robusteciendo el espacio disciplinar propio (Soussan, 2001).

Al mismo tiempo, irrumpe un interés creciente en cuestiones metacientíficas: el problema acerca de la naturaleza de la ciencia y los cambios históricos, las condiciones sociales de su producción, la reflexión sobre la ciencia como producción cultural apreciable, los recursos lógicos y discursivos que provee, los fines y valores regulando la actividad científica, etc. (Adúriz Bravo, 2005, 11-12).

La EC debe atender también a las complejas y acaso cambiantes condiciones de aprendizaje, de modo que su mirada debe incluir aspectos sociales, psíquicos, culturales, económicos e institucionales que exceden la mera intención de suministrar información científica, de una manera más o menos accesible, a aquellos que aún no lo poseen. Incluso en el nivel superior, la EC se propone objetivos que van más allá de la preocupación por preparar científicos bien capacitados en su especialidad.

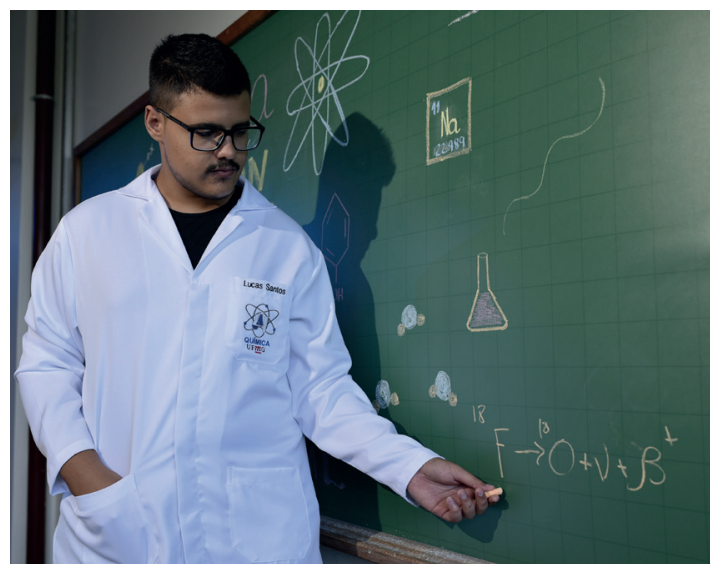

En suma, resaltaremos que la EC se constituye como un ámbito específico referido, sin dudas, a la ciencia; pero no circunscripto a ser una mera traducción de lo que efectivamente sería la actividad científica (Palma, 2008: 69)². Más bien, la EC se presenta con un desarrollo propio, desplegando un delimitado corpus teórico-disciplinar inducido por preocupaciones y objetivos particulares, no inmediatamente sujeto a la ciencia.

\section{El abordaje metacientífico de la EC}

En primer lugar, deberíamos al menos esbozar cómo podemos entender lo 'metacientífico': es el análisis o estudio de la ciencia en sus distintos aspectos; como un conjunto de técnicas o tipo de actividad productiva específica, como una organización institucional, como bien cultural, producto intelectual, etc.

Lo metacientífico no consiste en un saber de ciencia, sino sobre la ciencia. Se trata de ir más allá de la experticia que permite desempeñarse con éxito al científico en su área de especialización, esto es, su saber de ciencia. Pues se alude a un tipo de conocimiento contextualizador, que traza los vínculos entre las distintas disciplinas y las interconexiones con otros ámbitos de la vida social, encuadrando los fenómenos dentro de una visión histórica y estableciendo relaciones con distintas dimensiones de la vida social -lo educativo, lo económico, lo político, etc.- para extraer conclusiones referidas a la ciencia como acontecimiento global (Matthews, 2017, 16). Por sobre todo, el abordaje metacientífico supone un acto reflexivo que intenta perfilar una comprensión más penetrante de la ciencia, en contra de las concepciones más convencionales, espontáneamente aceptadas.

La cuestión metacientífica fundamental gira en torno de la pregunta: ¿qué es la ciencia? Se trata sin dudas de un amplísimo interrogante que debe dejar atrás las rígidas definiciones

2 Cabe aclarar, el epistemólogo Héctor Palma realiza esa afirmación en el marco de reconocer a la enseñanza de la ciencia como una actividad metacientífica que utiliza un lenguaje metafórico propio. Nuestro interés y punto de partida es diferente, pero converge en ese reconocimiento de la EC como discurso relativamente autónomo. 
escolarizadas y sumergirse en la vasta complejidad de un término mil veces utilizado en la cotidianeidad. De inequívoca existencia, la presencia de la ciencia es bien palpable y evidente entre nosotros, partícipes de la cultura moderna, pero a la vez suele ser percibida con cierta extrañeza y distanciamiento, rayando en la solemnidad y acaso en la fascinación ${ }^{3}$.

Por cierto, no es una mera pregunta ociosa, dado que habilita una extensa exploración acerca de los múltiples aspectos vinculados no solo con la producción de teorías científicas sino también con cierto tipo de hábitos, creencias, prácticas sociales, instituciones, ejercicio del poder y control social, desarrollo de la economía, producción de tecnología, etc. (Olivé, 2000, 27-29).

En las reconstrucciones filosóficas y en los análisis históricos se revela con mayor énfasis las controversias acerca de la definición de la ciencia. Como afirma León Olivé, destacado filósofo de la ciencia mexicano, responder a esa pregunta implica tener en cuenta las reflexiones metacientíficas, gestadas, por así decirlo, desde fuera de la ciencia, para ganar una visión más abarcadora de ella. Pero también debe considerarse la imagen interna de la ciencia, es decir, aquella que proviene de los mismos científicos acerca de sus propias actividades, propósitos, fines, productos y valores que los movilizan. Por último, no menos importante es la imagen pública de la ciencia, que aparece en los medios de divulgación y comunicación profesional e interpela a los destinatarios de

3 Muchas investigaciones alertan acerca del preocupante desconocimiento y sentimiento de ajenidad, en contraste con la presencia cada vez más masiva de la ciencia y el desarrollo tecnológico en la vida cotidiana actual. A la vez, pensadores como Pierre Thuillier (1990), han advertido acerca de la recurrente fascinación e idolatría por la Ciencia en la cultura moderna. Suele ocultar una ignorancia sobre ella y legitimar peligrosamente una dominación política tecnocrática. Como indicador de la misma problemática, León Olivé (2000: 45-65) ha señalado la frecuente oscilación social entre una fe ciega en la ciencia y una irracional desconfianza. estos mensajes como ciudadanos, presentando a la ciencia en cuanto a su relevancia cívica y social (Olivé, 2000: 42-43).

Por lo tanto, el abordaje metacientífico de la ciencia implicará transitar por estos tres tipos de imágenes que se corresponden a dimensiones o esferas de la actividad humana diferentes e irreductibles entre sí, y que constituyen la percepción de la ciencia.

Frente a ese panorama ofrecido por Olivé; no obstante, creemos que no se otorga suficiente atención a la $\mathrm{EC}^{4}$ pese a que su gravitación no es menor en la formación de las imágenes de la ciencia. Una visión errónea de la ciencia presupuesta en su enseñanza posee amplias repercusiones fuera y dentro de ella.

A propósito de ello, citaremos a Pierre Thuillier, filósofo e historiador de la ciencia francés:

Las sesiones de los «trabajos prácticos» de nuestro sistema de enseñanza contribuyen por otra parte a falsear las perspectivas [sobre la ciencia]. En efecto, los estudiantes experimentan la mayor parte de las veces sin acabar de darse cuenta de la amplitud del trabajo que ha sido necesario para perfeccionar nociones y los instrumentos que utilizan. De forma espontánea creen que eso es «evidente»; su único problema es realizar correctamente la manipulación (Thuillier, 1990, 12).

Según la apreciación de Thuillier, en las clases y en los libros de textos, las teorías científicas suelen aparecer como 'productos' o resultados de un quehacer metódico ya concluido, que el propio alumno simplemente deberá imitar o adoptar de manera más o menos automática. Entonces, se pasa por alto el carácter creativo,

4 Por momentos, en esa división tripartita, Olivé parece incluir la EC en la imagen científica o interna de la ciencia, en cuanto 'educación científica' sumado a la investigación (2000: 43). 
innovador, exploratorio, conjetural e incluso errático que suele tener una genuina investigación científica.

Por lo tanto, la EC puede cumplir un rol crucial en la reproducción de una imagen espontánea de la ciencia. Ya el célebre epistemólogo Thomas Kuhn había señalado la importancia de la educación, a través de los libros de textos y la práctica de resolución de problemas, para la necesaria adhesión acrítica del científico a su paradigma (Kuhn, 1980, 81-84).

Se podría objetar que se trata de una problemática ceñida al espacio puramente profesional. Sin embargo, sus efectos exceden largamente el ámbito exclusivo de la actividad científica.

Naturalmente, no podríamos medir con exactitud la incidencia de la EC en otras esferas de la actividad humana, pues las instituciones educativas formales conforman, en efecto, un inextricable tejido con el resto de las prácticas sociales, con los saberes, intuiciones y convicciones arraigadas y reproducidas de una manera difusa pero bastante efectiva en la sociedad. En todo caso, es indudable que el espacio del aula escolar, así como de la práctica del laboratorio y la educación científica en general constituyen lugares importantes de gestación, consolidación o amplificación de concepciones sobre la ciencia (Matthews, 2017, 17-19).

Lejos de ser solo un espacio de acceso al conocimiento científico, en donde se toma contacto con las teorías y se forma a un científico, los institutos de enseñanza pueden pensarse como importantes vehículos de concepciones acerca de la ciencia, que repercutirán e interactuarán con los medios de comunicación, los grupos familiares, el pensamiento del futuro científico y las perspectivas filosóficas.

En suma, podríamos afirmar que la EC actúa como punto de convergencia y correa de transmisión de sentido entre las diferentes imágenes o percepciones de la ciencia que aparecen entre los expertos científicos, el espacio público de divulgación y la mirada histórico-filosófica.

Ahora bien, resta responder también cómo debería ser una adecuada EC, cuáles serían sus principales finalidades, con qué criterios y medios se deberían contar, qué valores deberían regir su implementación, etc. En el siguiente apartado, abordaremos esas cuestiones, en líneas generales, apelando a la perspectiva teórica del destacado pensador contemporáneo Jürgen Habermas.

\section{El concepto de racionalidad comunicativa según Jürgen Habermas}

En principio, es menester advertir que el problema de la racionalidad aparece en un lugar central de su Teoría de la acción comunicativa, ese amplísimo programa teórico que Jürgen Habermas emprendió en los años 70 para desarrollar una Teoría de la sociedad y de la acción social, una Ética, una Teoría del Derecho, una Teoría política y una propuesta de reconstrucción del materialismo histórico y del giro pragmático en el lenguaje ${ }^{5}$.

5 Su intención global era llevar a cabo una considerable renovación teórica en el seno de la, así
Según Habermas, el problema de la racionalidad constituye un tema fundamental de la Filosofía desde sus inicios entre los griegos antiguos. Supone la búsqueda de un principio unificador en un orden que la razón traza y, a la vez, puede captar en el universo, en la

conocida, Teoría Crítica de la Escuela de Fráncfort. Mientras tanto, el despliegue teórico se ha bifurcado en múltiples debates en torno a la modernidad, el problema de la verdad, las concepciones evolucionistas, el constitucionalismo, etc., de modo que su Obra se torna muy difícil de catalogar y resumir en una sola etiqueta (Mc Carthy, 1995). 


\section{Habermas mantiene la intuición}

básica de que la racionalidad está

estrechamente vinculada con el

saber, pero le interesará desde

un punto de vista pragmático;

esto es, el saber o conocimiento

manifestado como práctica social,

en su uso efectivo.

sociedad y en la naturaleza, prescindiendo de explicaciones teológicas (1987a: 15).

No obstante, será la Teoría Social contemporánea, heredera de la Sociología decimonónica, la disciplina en mejores condiciones para aprehender lo racional en los procesos de modernización social, persiguiendo tanto los efectos progresivos como sus consecuencias negativas en la vida contemporánea.

A la vez, Habermas mantiene la intuición básica de que la racionalidad está estrechamente vinculada con el saber, pero le interesará desde un punto de vista pragmático; esto es, el saber o conocimiento manifestado como práctica social, en su uso efectivo.

No habría algo así como la Razón, esto es, una facultad o entidad metafísica o física en tanto nota esencial que definiría al hombre como animal racional. En cambio, se hace referencia a cierto tipo de competencias y habilidades -incorporadas individualmente por vía de la socialización y acreditada en la especie humana como logro evolutivo - que se aplican a circunstancias prácticas específicas. Utilizando la terminología de G. Ryle, consiste en un know how en un conjunto de destrezas no verbalizadas, pero que pueden explicitarse y convertirse en un know that. Tal proceso de explicitación involucra fundamentalmente al lenguaje; allí se verbaliza aquello no expresado, pero sí contenido en las propias prácticas, de manera que se va adquiriendo mayor conciencia acerca de lo que está operando en uno mismo y, a la par, se trata de comprenderlo mejor, de entender sus motivos, de revisar su justificación o razón de ser (Habermas, 1987ª, 15-19).

La necesidad de justificación acontece cuando, por algún motivo, se duda, se cuestiona y se revisa la práctica objetada ${ }^{6}$. Consideradas también como acciones, las propias emisiones lingüísticas son particularmente susceptibles de ser puestas en duda e inspeccionadas en sus contenidos proposicionales y fundamentos. Se indaga por qué o cuáles son las razones que justifican o sostienen tal afirmación o conducta; si son válidas o conviene desechar y cambiar ese comportamiento o enunciación lingüística. El proceso mismo de examen de validez implica esa explicitación antes referida como desarrollo lingüístico de las justificaciones.

Las emisiones lingüísticas -y las demás acciones no verbales-, procuran ser aceptadas; llevan consigo pretensiones de validez -o justificaciones- que pueden ser expuestas y revisadas. Habermas se referirá a cuatro tipos de pretensiones de validez que organizará en cuatro tipos de enunciados y acciones (189a, 25).

Por una parte, aludiremos a la pretensión de verdad, ligada a determinados tipos de emisiones o actos de habla como proposiciones o constataciones sobre posible estado de cosas; esas afirmaciones pretenden ser verdaderas y entonces se esgrimen argumentos que intentan apoyarlas.

La eficacia constituye una segunda pretensión de validez. En este caso, no se vincula solo a una emisión lingüística, sino también a una

6 En especial, el fracaso de alguna práctica o hábito. Aquí Habermas recupera la tradición pragmática en la teoría del conocimiento que puede remontarse al menos a las consideraciones del filósofo norteamericano Charles Peirce en torno a la fijación de las creencias. 
acción o intervención de un agente con el propósito de cumplir exitosamente con una finalidad propuesta. Se referencia a la racionalidad de tipo instrumental -al focalizarse en la aplicación de medios o instrumentos adecuados - y a la racionalidad estratégicaal hacer cálculos considerando también los cambios en la situación -. En el proceso de justificación se problematizaría la relación entre los medios escogidos y el fin establecido, examinando por qué se procedió con determinados recursos, según las circunstancias dadas o si efectivamente se logró el fin planeado.

En tercer lugar, califica como racional la capacidad de fundamentar una acción en cuanto si sigue alguna norma vigente en determinadas circunstancias y a la luz de ciertas expectativas de conducta. Se ponen en juego las normas que regulan las acciones, los principios y valores que suponen esas reglas, así como los enunciados de carácter normativo que aluden a ellas, en suma, la pretensión de corrección moral o rectitud.

En cuarta instancia, nombraremos a la autenticidad o veracidad como otro tipo de pretensión racional atribuida a todo aquel que intenta actuar de manera veraz al expresar algún aspecto de su subjetividad, tal como un deseo, sentimiento o cualquier otro estado de ánimo. En este caso, la única forma de demostrar la autenticidad o sinceridad de una vivencia interna subjetiva es a través de las acciones posteriores del propio actor que guarden cierta coherencia y logren convencer a los demás de esa pretensión (pp. 33-34). ${ }^{7}$

$7 \mathrm{Al}$ desarrollar en especial su Teoría de los actos de habla, Habermas refiere a cuatro pretensiones de validez que incluye la "inteligibilidad" o pretensión de cada enunciado de ser comprendido y excluye la "eficacia". Pero aquí nos abocamos a la clasificación derivada de su teoría de la acción social y al problema de la racionalidad implicado en ella. Se puede ver también su artículo "Aspectos de la racionalidad de la acción (1977)" (Habermas, 1997: 369-395)

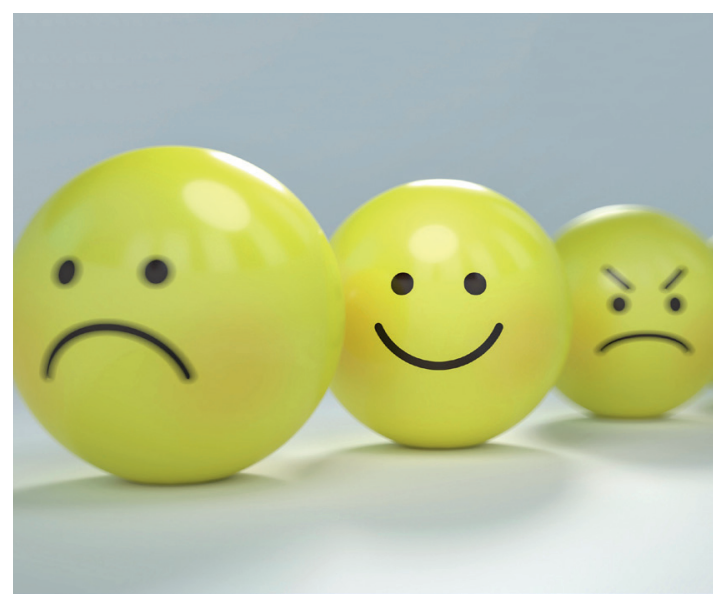

En suma, la racionalidad de cualquier enunciado o acción está relacionada a la capacidad de explicitar y someter a crítica sus propias pretensiones de validez, cualquiera sea ella. Si lo pensamos en términos de predicación hacia sujetos específicos, diríamos que racional es aquella persona dispuesta a recibir críticas y defender mediante razones o argumentos esa propia práctica o afirmación cuestionada. Por el contrario, irracional sería la actitud o la persona que se niega a someter a la crítica y a justificar sus afirmaciones o prácticas (pp. 33-35).

Este tipo de destreza, por así decirlo, no se aloja en el ser humano como una condición antropológica innata; más bien es el resultado de un proceso evolutivo histórico que incluye la afluencia y sedimentación de varias oleadas de racionalización social a la que aludiremos más adelante. Por el momento, solo llamaremos la atención en lo siguiente: estas transformaciones han sido dinamizadas sobre todo a partir de lo que Habermas denomina la lingüistización -Versprachlichung, [1981 a, 118] - de lo sagrado, que ha implicado un reemplazo paulatino de prácticas rituales por la acción comunicativa, en tanto el consenso social va quedando gradualmente en manos de justificaciones lingüísticas y no por algún tipo de autoridad sacra actualizada en el rito (1987b,112). 
La lingüistización constituye un componente clave para explicar desde el punto de vista histórico y social, las condiciones de desenvolvimiento de la racionalidad comunicativa. Ella supone un quiebre en la aceptación espontánea de las imposiciones tradicionales consideradas sagradas y una intensificación de la utilización del lenguaje como mecanismo para coordinar las acciones, pero también para revisarlas y corregirlas. A la vez, crece la conciencia individual o la relación reflexiva del actor con respecto a sus propias prácticas: es capaz de responder por sus actos $y$, entonces, comportarse críticamente; eso también se extiende, por supuesto, a sus expresiones lingüísticas con distintas pretensiones de validez (Habermas, 1987b, 110).

Las pretensiones de validez van de suyo con cualquier expresión lingüística y acción, en tanto manifestación simbólica. Más allá de si efectivamente se examinen o no esas pretensiones, son constitutivas e inmanentes a las propias prácticas humanas. Están allí, alojadas en nuestro lenguaje, en las interacciones, como un potencial que puede desplegarse o no.

\section{La argumentación: racionalidad comunicativa y teoría científica}

Desde el punto de vista comunicativo, lo racional estará dado fundamentalmente por la capacidad de desarrollar justificaciones mediante argumentos. Pues bien, una Teoría de la Argumentación vendrá a complementar la concepción habermasiana de racionalidad, pues allí se reconstruirán las estructuras específicas y las regulaciones de tal procedimiento de carácter eminentemente lingüístico-pragmático ${ }^{8}$.

Cabe subrayar que, desde al menos mediados del siglo XX, la Filosofía de la Ciencia ha incrementado su interés en la argumentación como objeto de estudio de una 'lógica informal' que reconoce como fundamental la dimensión práctica de las teorías científicas, sus componentes retóricos y fuerza persuasiva, su encuadramiento en interacciones, la gravitación del 'auditorio' y su vinculación con el lenguaje ordinario?.

8 Habermas sigue sobre todo la perspectiva desarrollada por S. Toulmin, con algunas críticas (1987a: 43-69).

9 En el año 1958 aparecen dos libros considerados ya clásicos del tratamiento: Los usos de la argumentación de Stephen Toulmin y el Tratado de la argumentación de Chaïm Perelman en colaboración con C. Olbrechts-Tyteca. Para un
En consonancia con la crítica general -a partir de los aportes de la filosofía de la ciencia vinculada con la historia y sociología de la ciencia - a una visión estandarizada y ortodoxa de la ciencia como un conjunto de proposiciones ligadas entre sí bajo reglas y procedimientos lógicos formales, el razonamiento científico ya no puede acotarse a una estructura puramente formal inductiva $o$ deductiva, sino que alude a relaciones internas dadas por las condiciones de uso del lenguaje. Por caso, las evidencias y el trabajo empírico en general cuentan siempre como elementos incrustados en determinados marcos categoriales que hacen a un argumento específico, bajo una interpretación dada, utilizadas para ciertos fines y propósitos, etc.

Una epistemología ampliada comprende a las teorías científicas como desarrollos argumentativos que constituyen también prácticas lingüísticas situadas en determinadas interacciones, sujetas a condiciones sociales e históricas de aplicación.

panorama de la Teoría de la Argumentación y teoría científica, se recomienda el trabajo de Asti Vera, Carlos y Ambrosini, Cristina, Argumentos y teorías. Aproximación a la Epistemología (2010) 
A su vez, la validez de los argumentos no se puede medir a través de un cálculo matemático ni estimar en una inferencia puramente deductiva. Aunque tampoco su validez permanezca condenada a la indeterminación o inconmensurabilidad. A grandes trazos, las teorías de la argumentación se han esforzado por demostrar que es posible reconocer y evaluar a los argumentos en cuanto a la consistencia y pertinencia de sus razones en el intento de convencer a unos participantes en un diálogo. En otras palabras, la consideración del argumento se hace en virtud de su fuerza de convencimiento.

Desde luego que la estimación de la fuerza o consistencia de un argumento no nos conducirá a una verdad absoluta sino a una validez provisoria, siempre sujeta a nuevas revisiones y a la eventualidad de encontrar mejores argumentos, abriendo la posibilidad de aprendizaje a partir del descubrimiento de errores y límites mientras se desarrolla un autocercioramiento o la crítica recíproca.
Habermas insiste en recalcar que, en un sentido ya muy especial, el comportamiento racional implica sobre todo la capacidad de superar autoengaños o el aprender a partir de los errores, ampliando, ajustando, complejizando y renovando el mismo lenguaje; así se van desechando, seleccionando, corrigiendo y mejorando los argumentos $\left(1987^{\mathrm{a}}, 43\right)$.

$\mathrm{Al}$ mismo tiempo, hablar de fuerza de convencimiento nos remite a la capacidad vinculante que posee la práctica argumentativa -o bien podríamos ya decir la racionalidad comunicativa en un sentido primordial-con respecto a la praxis de los agentes.

Más precisamente, Habermas habla de 'motivación racional' aunque ella debe lidiar, y muchas veces aparece entremezclada, con las llamadas 'motivaciones empíricas' o coerciones de distinta índole. En todo caso, la razón comunicativa aparece siempre como una débil coacción en tensión con las demás imposiciones y condicionamientos intrapsíquicos, sociales, culturales, materiales, etc.

\section{Condiciones mundanas e idealizaciones de la racionalidad comunicativa}

Asimismo, el abrirse a la argumentación significa que las pretensiones de validez se van a desempeñar en un proceso intersubjetivo de explicitación de razones que fundamentan las prácticas o emisiones objeto de cuestionamiento. Aquí ingresamos en la instancia, denominada por Habermas, del discurso.

En el discurso, las afirmaciones y reglas normativas puestas en cuestión adquieren el estatuto de conjeturas e hipótesis; se examinan los argumentos disponibles, se buscan otros, se indagan sus límites, etc. Irremediablemente, la práctica queda en suspenso; los enjuiciamientos espontáneos y saberes intuitivos se convierten en objeto de duda y revisión. La contraparte del discurso es la acción, el ámbito en donde transcurre la vida cotidiana sin cuestionamientos, ejecutando las prácticas ya instituidas o hábitos consagrados, aunque siempre permeables a la influencia del discurso racional.

Desde luego que tal situación discursiva exige unas condiciones especiales de igualdad o simetría entre los participantes, de absoluta libertad y la anulación de cualquier restricción. Se trata de condiciones ideales, que Habermas cristalizó con la expresión situación ideal del diálogo. Como tal, esa idealización no se concretiza de forma plena, pero opera como un supuesto pragmático ineludible en los propios participantes y posee cierta efectividad en las prácticas concretas. Está presente como suposición básica en cualquier intento de cuestionamiento y debate intersubjetivo; 
funciona como criterio para evaluar el carácter condicionado de cada debate y a la vez opera como una fuerza a contrapelo de las limitaciones concretas que presenta cada situación.

Por lo demás, tenemos aquí una concepción comunicativa de la racionalidad constituida en un tipo determinado de relación o vínculo entre subjetividades. Carece de sentido examinar pretensiones de validez ni plantear argumentos sin interlocutores, reales o virtuales.

El trasfondo general es una crítica a las versiones estrechas de la racionalidad concebidas exclusivamente como instrumental, o como funcional $^{10}$. En el primer caso, supone la situación solitaria y monológica de un sujeto enfrentado a su objeto - aun cuando el objeto sea un individuo - en actitud de control y dominio; en el segundo caso, conlleva el supuesto de un mecanismo global anónimo o desubjetivado, actuando siempre a espaldas de los propios individuos que exige, de continuo, una actitud adaptativa.

Cabe aclarar, no es que Habermas niegue la racionalidad en términos funcionales o instrumentales, sino que pretende partir de una base pretendidamente más amplia que señale los límites y condicionamientos de esas otras formas de la razón ${ }^{11}$.

Su enfoque comunicativo intenta recobrar un sentido más pleno de la razón vinculado con la antigua idea de logos, como unión mediante el diálogo argumentativo libre, sin coerciones de ningún tipo (Habermas, 1987ª, 27). La razón,

10 También pretende ser amplia en el sentido de que integra aspectos que van más allá de lo cognitivo, afectando lo valorativo-moral, lo expresivo y estético.

11 La perspectiva comunicativa pretende abarcar e incluir las demás versiones de la racionalidad, en el siguiente sentido: aún las formas más complejas de racionalidad sistémico-funcional e instrumental anclan en formas institucionalizadas asentadas en una base comunicativa; en ellas subyacen siempre una pretensión de legitimidad discursiva. incrustada en el lenguaje impulsa, en última instancia, hacia un entendimiento no coactivo con el otro (p. 110), que no significa la homogenización de los individuos, ni su fusión en una totalidad uniforme y, menos aún, una milagrosa o quimérica comunión de pensamientos.

Por el contrario, la exigencia de libertad permite abrir y desplegar los conflictos, las disidencias, las diferencias irreductibles $y$, en todo caso, contrarrestar la autoafirmación cerril y las distorsiones sistemáticas ocasionadas justamente por las coacciones estructurales. De ninguna manera se niegan o desconocen todos esos elementos a los que estamos tan habituados en nuestras interacciones cotidianas; pero, en tanto queremos convencer al otro de manera genuina sin coaccionarlo de manera abierta o velada, debemos recurrir a buenos argumentos para pretender el reconocimiento de nuestras razones como válidas y así alcanzar un entendimiento mutuo ${ }^{12}$; sin imponernos de manera unilateral.

Esto es, en determinadas condiciones intersubjetivas que supongan fundamentalmente el estar liberados de coacciones y del ejercicio de la violencia o el poder coercitivo, el lenguaje, por así decirlo, persigue su propia finalidad de generar consenso por medio de argumentos.

No obstante, tal entendimiento completamente libre de cualquier situación de dominio que produzca desigualdades y asimetrías entre los participantes -e incluso la exclusión en el diálogo- la entenderá Habermas como una situación ideal de diálogo. Aunque también hemos subrayado que su carácter ideal no

12 Cabe aclarar que Habermas luego distingue entre un entendimiento básico o elemental que supone el compartir una base sin alcanzar una coincidencia en las razones esgrimidas y un sentido más fuerte que supone estar convencido por idénticos argumentos. Vale decir, la búsqueda de un acuerdo pleno sin coacciones opera como un télos permanente en nuestras prácticas lingüísticas, aun cuando también están fuertemente mediadas y limitadas por otros condicionantes. 
implica una mera aspiración inalcanzable, sino una pretensión, inevitablemente presente en cada intervención comunicativa de actuar y orientar con cierta fuerza fáctica en la acción, en tirante relación con los límites que imponen las condiciones reales de comunicación (p. 29).

Conviene añadir que cada práctica comunicativa no se agota en todo aquello manifiesto en el lenguaje. Esas idealizaciones inmanentes -referidas anteriormente- apuntan siempre más allá de cada situación concreta. Si se quiere, la racionalidad comunicativa es a la vez inmanente a las prácticas sociales y trascendentales a ellas. Por eso, a pesar de las condiciones adversas en las que se suelen dar las interacciones -desigualdad, indiferencia, exclusión, censura, amenazas, temor, etc.-, el mismo carácter contrafáctico de la racionalidad comunicativa puede organizar el tipo de relación intersubjetiva entablada a contrapelo de los propios condicionamientos fácticos $\mathrm{o}$, al menos, poner en tensión esa determinación situacional (Habermas, 2003).

Es menester destacar la intención de otorgar un carácter situado a la racionalidad comunicativa. Aquí Habermas pretende proseguir la tradición filosófica poshegeliana que ha puesto en entredicho las versiones trascendentales o excesivamente especulativas de la razón. Las tentativas de "destrascendentalizar" la razón, reconociendo su raigambre histórica y social, implica principalmente su reivindicación sin una base metafísica sospechosa de ser una vacía ilusión (Habermas, 1990).

Así pues, el hecho de que la razón se configura de manera lingüística y pragmática supone, en el caso de Habermas, un mundo de la vida como trasfondo imprescindible. El mundo de la vida representa siempre un conjunto de intuiciones, saberes y evidencias sedimentadas en una cultura determinada que a su vez provee de recursos simbólicos necesarios para orientar la práctica cotidiana. Son siempre históricos y sociales, conforman capas profundas, envolventes y contextualizadoras de los saberes

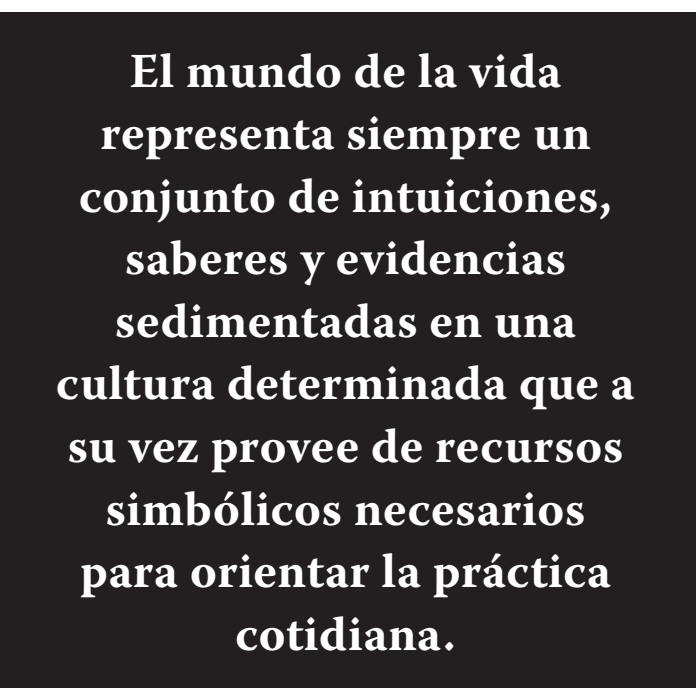

acreditados de manera individual en la vida cotidiana. Se trata de un tipo de conocimiento preteórico no completamente a disposición de un abordaje metódico deliberado. Opera, por así decirlo, a espaldas de los propios agentes que portan ese saber (1987b, 169-210).

Con todo, resulta falaz sostener a priori que el mundo de la vida - o parte de él- es intrínsecamente inmune a la racionalidad comunicativa. El ejercicio crítico es posible justamente porque el mundo de la vida es también la fuente de las competencias pragmáticas y de los recursos lingüísticos que permiten participar como dialogantes en un debate racional. Si bien solo internalizando una estructura simbólica mundana podemos llegar a comprenderla e incluso a cuestionarla.

En suma, el proceso crítico opera desde dentro del mundo de la vida y en actitud de diálogo ya sea efectivo o virtual-con los demás ${ }^{13}$. Suele funcionar más bien de forma acotada y recorre un trayecto reflexivo-circular al convertir en objeto de cuestionamiento elementos puntuales del mundo de la vida ya presupuestos en las propias vivencias mundanas de sus participantes.

13 Lo opuesto sería un vínculo monológico de exterioridad con respecto al objeto de indagación. 


\section{Racionalidad comunicativa y racionalización social}

Desde luego, las competencias comunicativas para el diálogo son productos de un determinado proceso histórico. Habermas, ha emprendido también un enfoque socioevolutivo que introducirá los distintos mecanismos de racionalización para explicar las condiciones históricas que hacen a la disposición de la racionalidad comunicativa como práctica social.

En efecto, nuestro autor se ha esforzado en delimitar al menos dos vías de racionalización diferentes que responde a dos modalidades irreductibles de racionalidad ya aludidas: por una parte, un desarrollo instrumental y funcional que implica el incremento de la capacidad técnica de producción y las diferenciaciones progresivas que hacen a una complejización organizativa funcional, en vistas a una optimización en el mantenimiento y expansión sistémica. Las instituciones típicas de las sociedades modernas, como la economía de mercado y la administración estatal constituyen las objetivaciones históricas más emblemáticas de este proceso de racionalización técnico y funcional.

Por otra parte, contamos con una evolución de carácter lingüístico-normativo que alude al proceso de racionalización del mundo de la

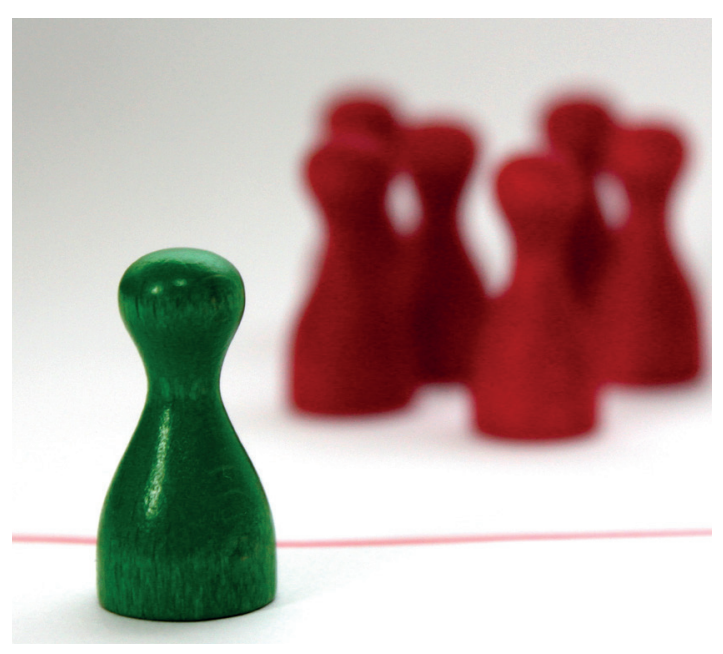

vida incluyendo también una diferenciación interna de sus componentes considerados estructurales, a saber, la personalidad, la sociedad y la cultura. El mundo de la vida se racionaliza en dirección hacia una intensificación progresiva de la lógica discursiva en ámbitos de la vida social como la familia, la educación de los niños, la tradición cultural, las normas sociales, el derecho, etc. Dicho proceso implica una flexibilización de las solidaridades comunitarias heredadas, una debilitación de la coerción cultural tradicional, la construcción identitaria individual menos rígida, un desarrollo cognitivo de diferenciación y descentración de las imágenes del mundo $^{14}$ en el marco de una expansión de los espacios sociales - concebidos como espacios públicos- para ejercer la crítica y el disentimiento. Tal fluidificación lingüística exige una regulación institucional y legal bajo principios cada vez más abstractos y generales, capaces de incluir y habilitar el desarrollo de esa diversidad y el incremento de su complejidad.

Las interacciones mediadas lingüísticamente operan como reproductoras dinámicas de su medio; la racionalidad comunicativa se constituye en el mundo de la vida, pero a su vez lo va reproduciendo, actualizando, renovando, etc.

14 Por una parte, nos referimos a la diferenciación formal entre mundo subjetivo -intrapsíquico-, mundo social -intersubjetivo - y mundo objetivo - como estado de cosas existentes- que no se confunden entre sí. Tal deslinde opera como marco de referencia para el proceso de "descentración" en la comprensión capaz de distinguir la naturaleza objetiva de los hechos, frente a las vivencias y perspectivas subjetivas propia y de los demás, a diferencia también a reglas y normas sociales que reclaman una validez compartida (1987b: 101-103). Con ello, Habermas pretende proyectar algunos aspectos centrales de la teoría del aprendizaje de Jean Piaget en la explicación del tránsito de una mentalidad mítica y religioso-metafísica hacia el pensamiento moderno. 
Sin embargo, en la progresiva lingüistificación de sus estructuras fundamentales, el mundo de la vida deviene más frágil y permeable a las influencias de los procesos de racionalización instrumental y sistémica. La expansión sin frenos de la economía capitalista y del dominio estatal se convierten en la amenaza más importante para las relaciones sociales vitales sostenidas por la comunicación lingüística y las instituciones en ese medio. Así, el poder económico y estatal tienden a colonizar una esfera pública y una educación pretendidamente autónoma, condiciona el ejercicio efectivo de una política deliberativa, la vigencia de un régimen democrático y el orden constitucional en el marco de un Estado de derecho. En fin, se da una especie de dialéctica de la racionalización social que contiene aspectos paradójicos y contradictorios (1987b, 469-502).
No obstante, la concepción de la racionalidad comunicativa de Habermas así como su perspectiva evolutiva del mundo social adolecen de innumerables críticas. Sin dudas, las más frecuentes versan acerca del carácter teleológico, pese a Habermas, y pretendidamente universal de esa evolución, que disminuye su presunta pluralidad. En el fondo, puede estar subyaciendo una visión estrecha de la racionalidad que deja de lado otras posibilidades culturales y saberes sociales calificados, sin más, como irracionales (Giddens et al., 1991).

No nos podemos aquí ocupar de las arduas polémicas en torno al presunto eurocentrismo de Habermas y a los problemas subyacentes en su concepción comunicativa de la racionalidad. Pero sí podemos abordar, aunque no sea más que brevemente, algunas repercusiones de esta cuestión en el tratamiento metateórico de la ciencia y algunas posibles objeciones.

\section{El carácter procedimental de la racionalidad comunicativa}

Más allá de los temas y contenidos que se pueden abordar en cualquier situación discursiva, la mirada habermasiana se focalizará en el procedimiento. El procedimiento constituye la unidad en la pluralidad de las voces (1990, 155-187); el aspecto que no se debe resignar a buscar en común en las siempre harto cambiantes circunstancias de debate, de confrontación retórica, de intercambios de opiniones.

En su carácter procedimental, la razón no está comprometida con ningún punto de vista particular, con ninguna cosmovisión ni posición ética substancial. Lo importante son las condiciones y reglas bajo las cuales se interrogan, comparan y ponen en tensión diferentes puntos de vista.

Pero eso no significa que la racionalidad comunicativa consista en una entidad inmaterial puramente formal; a tal punto despojada de cualquier materialidad y sustancialidad que devendría vacía e inocua.
En realidad, lo procedimental no equivale estrictamente a lo formal y, por lo tanto, la razón comunicativa no se constituye en lo contrario de lo substancial. Bien entendido, el procedimiento racional en la comunicación discursiva porta consigo una serie de normas y valores que implican un posicionamiento ineludible a favor de la libertad plena, de los espacios de debates irrestrictos, de la igualdad de los participantes, de la conciencia falibilista ${ }^{15}$, de la tolerancia y apertura hacia los puntos de vistas ajenos, de respeto absoluto a la integridad personal de cada individuo, de rechazo categórico al dogmatismo - cualquiera sea la procedencia- y una disposición a la autocrítica y al aprendizaje continuo. La racionalidad, per $s e$, no es desinteresada ni neutral.

15 Habermas también ha referido a su noción de razón como portadora de una actitud típicamente escéptica más no derrotista (1990: 9) 


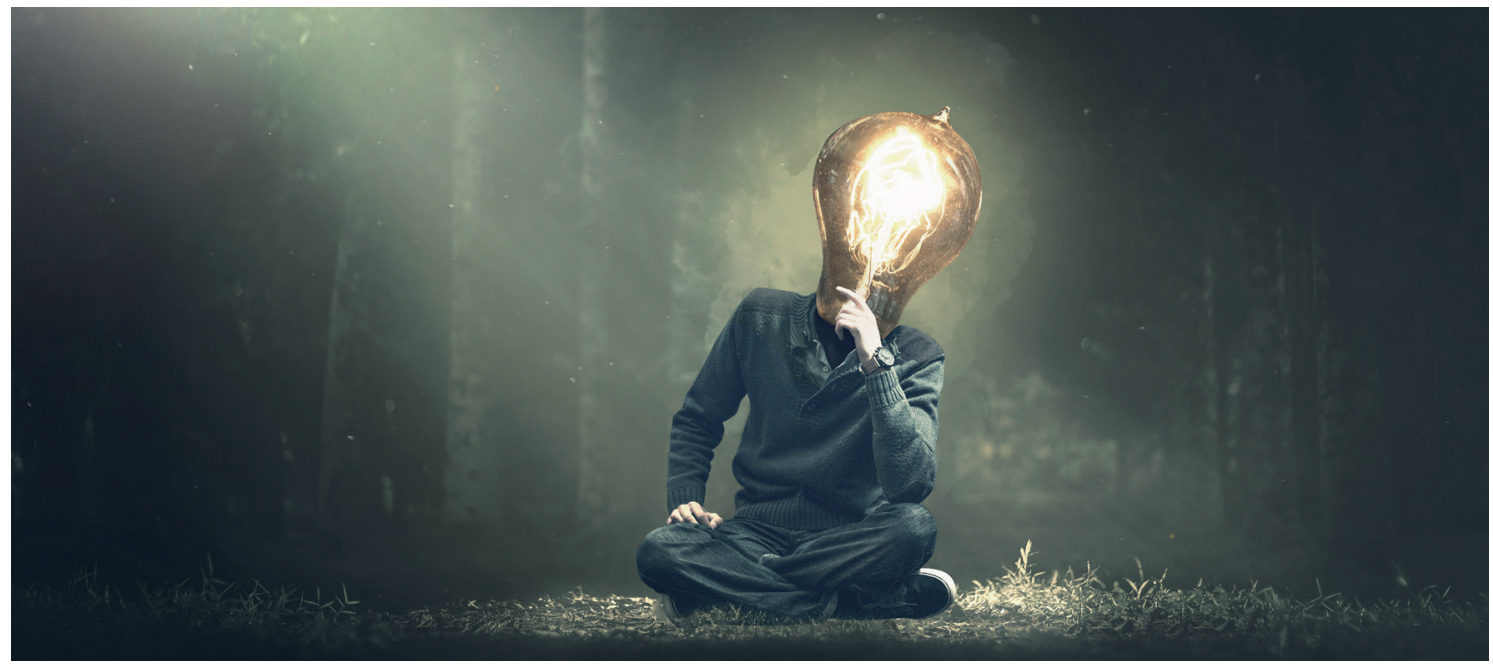

\section{9. Últimas consideraciones en torno a la racionalidad comunicativa en conexión con la Enseñanza de la Ciencia desde una mirada metacientífica}

El hecho de que la EC en sus distintos niveles deba hacer accesible el conocimiento científico y promocionar el pensamiento crítico, nos mantiene todavía en una indeterminación muy amplia y deja abierto muchos interrogantes: ¿qué se debe enseñar? ¿qué aspectos de la ciencia son relevantes para una enseñanza en sus distintos niveles? ¿Se genera pensamiento crítico con solo tener acceso a la ciencia?

Por otra parte, el desarrollo mismo de la enseñanza de la ciencia y sus derivaciones en didácticas específicas de cada disciplina señalan también que el simple contacto con la ciencia, en algunas de sus formas más elementales, o más complejas, no asegura automáticamente un pensamiento crítico. Incluso, se hace susceptible de reproducir imágenes ideologizadas en formas cientificistas. La EC puede ser un elemento crucial de carácter dogmático y estereotipado de la ciencia, más conservador incluso de lo que el mismo Thomas Kuhn ha estimado ${ }^{16}$.

16 Por ejemplo, se ha afirmado: "No parece haber ninguna buena razón para creer, entonces, que el mero hecho de transmitir algunos contenidos con
Sin embargo, la EC no está destinada fatalmente a ser así. Su consolidación como ámbito específico en diálogo con otras disciplinas vinculadas a las didácticas y el aprendizaje muestran, por el contrario, un esfuerzo de renovación permanente.

No menos importante resulta el aporte de la reflexión epistemológica. Hemos ya señalado la importancia de las disciplinas metacientíficas en la EC, en cuanto a proveer de una visión crítica acerca de la ciencia, nutrir de una actitud reflexiva y creativa con respecto a

alguna vinculación a la ciencia, conllevarían consigo, merced a una suerte de empatía que finalmente no es tal, el despertar del pensamiento crítico en los estudiantes" (Palma, 2008: 100)

El autor anteriormente citado, Héctor Palma, ha dicho también que la pretensión de estimular el pensamiento crítico ha llegado a constituir un mito de la EC, pues solo se trata de una consigna vacía y que, en el mejor de los casos, con los recursos didácticos más refinados y eficientes, se logra alguna mínima comprensión o acercamiento a la ciencia en los niveles preuniversitarios y una adquisición de las habilidades específicas en la formación profesional del científico (Palma, op. cit::101). 
las prácticas, desarrollar una reflexión acerca de los fines de la ciencia y sus implicancias éticas, su compromiso social, sus connotaciones políticas e ideológicas, etc.

Por ese camino, proponemos recuperar la posición que ha sustentado el pensador contemporáneo alemán Jürgen Habermas en torno a la racionalidad comunicativa, bosquejando una posible visión metacientífica de la ciencia, que nos permita además abordar el problema de la EC de una manera enriquecedora.

Sin dudas, la racionalidad comunicativa bajo la perspectiva habermasiana refiere a aspectos fácilmente reconocibles en la propia ciencia: las investigaciones requieren de la supervisión de los especialistas, los resultados deben publicarse y someterse a la revisión de pares expertos, el conocimiento se produce con la mayor libertad y la menor limitación posible: existe una conciencia clara acerca del carácter provisorio de los logros alcanzados, etc.

Sin embargo, la práctica científica no es reducible sin más a unos procedimientos racionales más o menos estandarizados. La reconstrucción metateórica de la ciencia que se podría llevar a cabo a partir de la concepción comunicativa de racionalidad podría ser impugnada por demasiada idealista e ingenua. En particular, los estudios históricos y sociales han suficientemente demostrado que el trabajo en la comunidad científica suele estar fuertemente restringido y jerarquizado; es presa continua de los intereses 'extra-epistémicos' relacionados con el ejercicio del poder político, los planes belicistas, el impulso mercantilista y productiva, etc. (Thuillier, 1990).

Al mismo tiempo, es posible constatar históricamente una multiplicidad de formas que ha adoptado el quehacer científico, sin ajustarse a la versión procedimental antes aludida ${ }^{17}$.

17 Un ejemplo, que puede claramente ilustrar, es el caso Pasteur analizado por Pierre Thuillier, como la actitud autoritaria, dogmática y prejuiciosa; sin
Tampoco se concluye necesariamente que la ciencia estaría plagada de irracionalidad; el punto es ampliar aún más la noción de racionalidad de modo que contenga diversas prácticas que hacen a la ciencia. En particular, las posturas epistemológicas inscriptas en la estela de Thomas Kuhn, atento a una perspectiva enfáticamente histórica sobre la ciencia, han remarcado el carácter diverso de lo racional en la ciencia (Pérez, 1999) de modo que el propio planteo habermasiano puede ser objetado de indebidamente 'apriorístico'.

Aun así, Habermas apunta hacia una peculiaridad en la ciencia cuya ausencia la desdibujaría por completo; se tornaría imposible especificarla entre las diversas prácticas humanas. Pues resultaría absurdo imaginar a la actividad científica carente totalmente de criticismo intersubjetivo. Toda producción de conocimiento científico debe presumir un grado mínimo de libertad comunicativa y el examen genuino de argumentos; de lo contrario, deberíamos aceptar que la ciencia constituye una gran maquinaria que solo recrea relaciones de poder e impone productos ideológicos.

En ese sentido, la EC debe situar en un primer plano el ejercicio del pensamiento crítico y reflexivo, alentar la actitud conjetural, exploratoria, argumentativa y creativa ${ }^{18}$, mostrando la importancia del trabajo colaborativo, el intercambio de pareceres y, al mismo tiempo, las disputas y controversias en el desarrollo científico; la coexistencia de puntos de vistas y esquemas interpretativos diferentes que deben dirimirse; el carácter provisorio de las conclusiones y los productos de las investigaciones. $\mathrm{La}$ EC debe propiciar un clima favorable al intercambio de opiniones, animar al compromiso

embargo, contribuyó de manera fundamental en el desarrollo de la microbiología (412-438).

18 No se trata de una proclama vacía, pues existen experiencias de EC promoviendo, por ejemplo, el desarrollo de la práctica argumentativa incluso en los niveles más temprano de la educación (Pérez, 2020) 
cooperativo por la búsqueda de la verdad, al examen e intercambio de argumentos, a superar nuestros propios puntos de vista más o menos cerrados para ir incorporando a perspectivas más amplias; que somos capaces, en fin, de aprender.

Así pues, las preocupaciones de la EC no deben restringirse a la transmisión de contenidos o al problema del acceso a la información científica - menos aún como si fueran verdades incontrovertibles-. La instrucción de científicos avezados y la divulgación más efectiva de los logros científicos a la ciudadanía no pueden proponerse como finalidades exclusivas. Estimulando los aspectos que hemos denominados procedimentales, contenidas en la racionalidad comunicativa y reconocidas en la práctica científica, la EC debe promover también una actitud crítica para el ejercicio de una ciudadanía activa y el cultivo de un pensamiento más autónomo.

\section{Referencias}

Acevedo, J. (2004) "Reflexiones sobre las finalidades de la enseñanza de las ciencias: educación científica para la ciudadanía", Revista Eureka sobre Enseñanza y Divulgación de las Ciencias, Vol. 1, $\mathrm{N}^{\circ} 1$, Universidad de Cádiz, España, pp. 3-15.

Adúriz, A. (2005) Una introducción a la naturaleza de la ciencia. La Epistemología en la enseñanza de las ciencias naturales. Fondo de Cultura Económica.

(2011) "Desde la enseñanza

de los 'productos de la ciencia' hacia la enseñanza de los 'procesos de la ciencia' en la Universidad" Colección de Cuadernillos de Actualización, año 6, $\mathrm{N}^{\circ}$ 3, Universidad Nacional de Río Cuarto, noviembre de 2011, pp. 5-15

Asti, C.; Ambrosini, C. (2010). Argumentos y teorías. Aproximación a la Epistemología. C. C, C. Educando.

Badillo, R. et. al (2002) Historia de la Didáctica de las ciencias: un campo de investigación en Revista TED Tecné, Episteme y Didaxis, $\mathrm{N}^{\circ} 12$, Facultad de Ciencia y Tecnología, Universidad Pedagógica Nacional.

Beltrán, A. (1995). Revolución científica, renacimiento e historia de la ciencia. Siglo XXI.

Crujeiras, B. et. al. (2020). "Trabajar la argumentación a través de un juego de rol: ¿debemos instalar el cementerio nuclear?" en Enseñanza de las Ciencias, 28 (3), Universidad de Valencia, pp. 125-142.

Giddens, A. et. Al. (1991). Habermas y la modernidad. Cátedra.

Gil, D. (1994). "Diez años de investigación en Didáctica de las Ciencias: realizaciones y perspectivas" en Enseñanza de las Ciencias, 12 (12), Universidad de Valencia, pp. 154-164.

Gimeno Lorente, Paz (2009) Didáctica, crítica y comunicación. Un diálogo con Habermas y la Escuela de Frankfurt. Octaedro.

Habermas, Jürgen (1987a) Teoría de la Acción Comunicativa. Tomo I. Racionalidad de la accióny racionalización social. Taurus. (vers. orig.: [1981a] Theorie des kommunikativen Handelns. Band 1. Handlungsrationalität und gesellschaftliche Rationalisierung. Suhrkamp Verlag.)

- (1987b) Teoría de la Acción Comunicativa. Tomo II. Crítica de la razón funcionalista. Taurus. (vers. orig.: [1981b] Theorie des kommunikativen Handelns. Band 2. Zur Kritik der funktionalistischen Vernunft. Suhrkamp Verlag.)

$$
\text { (1990) Pensamiento postmeta- }
$$

físico. Taurus

(1997.) Teoría de la acción comunicativa. Complementos y estudios previos $\left(3^{\circ}\right)$. Cátedra. 
. (2003). Acción comunicativa y razón sin trascendencia. Paidós.

Kuhn, Th. (1980). "Los paradigmas científicos" en Barnes, B. y otros. Estudios sobre Sociología de la Ciencia. Alianza, pp. 79-102

. (2004). La estructura de las revoluciones científicas (2da). Fondo de Cultura Económica.

Laudan, L. (1997). "La teoría de la investigación tomada en serio" en Velazco Gómez, Ambrosio (comp.). Racionalidad y cambio científico. Paidós, pp. 25-41.

Matthews, M. (2017). La enseñanza de la ciencia. Un enfoque desde la historia y de la filosofía de la ciencia. Fondo de Cultura Económica.

McCarthy, Th. (1995). La teoría crítica de Jürgen Habermas. Tecnos. Moulines, C.
Ulises (1982) Exploraciones metacientíficas. Estructura, desarrollo y contenido de la ciencia. Alianza Editorial.

Nieto-Galán, A. (2011). Los públicos de la ciencia. Expertos y profanos a través de la historia. Marcial Pons.

Olivé, L. (2000). El bien, el mal y la razón. Facetas de la ciencia y la tecnología. Paidós.

Palma, H. (2008). Metáforas y modelos científicos. El lenguaje en la enseñanza de las ciencias. Libros del Zorzal.

Pérez, A. (1999). Kuhn y el cambio científico. Fondo de Cultura Económica.

Soussan, G. (2001). "La investigación didáctica de las ciencias experimentales". Revista de Investigación, vol. 50, Venezuela, pp.15-23

Thuillier, P. (1990). De Arquímedes a Einstein. Las caras ocultas de la invención científica. Vol. 1 y 2. Alianza Editorial. 